\title{
ANALISIS TECHNOLOGY ACCEPTANCE MODEL APLIKASI LINKAJA
}

\author{
Anggit Esti Irawati ${ }^{1)}$; Ehrmann Suhartono ${ }^{2)}$ \\ anggitestira@staff.uty.ac.id ${ }^{1)}$; indahdesaku@gmail.com ${ }^{2}$
}

Program Studi Akuntansi, Universitas Teknologi Yogyakarta, Yogyakarta, Indonesia

\begin{tabular}{|c|c|}
\hline Info Artikel & bstrak \\
\hline Sejarah Artikel: & $\overline{\text { Potensi penggunaan e-money sangat besar dan menarik perhatian sebagai cara pembayaran alternatif }}$ \\
\hline Diterima: 19-11-2020 & di seluruh dunia. Pemerintah melalui Bank Indonesia menggerakkan masyarakat untuk melakukan \\
\hline Disetujui :28-12-2020 & Gerakan Nasional Non Tunai (GNNT). Namun, hanya lapisan masyarakat tertentu yang sudah terbiasa \\
\hline Dipublikasikan:30-12-2020 & $\begin{array}{l}\text { menggunakan transaksi dengan e-money. Sebagian masyarakat beranggapan bahwa transaksi } \\
\text { pembayaran menggunakan e-money masih terdapat banyak kekurangan. Penelitian ini bertujuan untuk }\end{array}$ \\
\hline $\begin{array}{l}\text { Keywords: } \\
\text { actual use; attitude }\end{array}$ & $\begin{array}{l}\text { menguji Technology Acceptance Model (TAM) yaitu perceived ease of use dan perceived usefulness, } \\
\text { selain itu juga menambahkan perceived risk untuk mengetahui pengaruh terhadap attitude toward using }\end{array}$ \\
\hline towrads using; perceived & dan actual use terhadap penggunaan aplikasi LinkAja. Metode analisis menggunakan Structural Equation \\
\hline ease of use; perceived & Modeling (SEM) dengan alat analisis SmartPLS. Penelitian ini dilakukan dengan metode survei dan \\
\hline usefulness; perceived risk & $\begin{array}{l}\text { sampel diambil menggunakan teknik purposive sampling terhadap responden yang menggunakan } \\
\text { aplikasi LinkAja di seluruh Indonesia. Responden yang diperoleh sebanyak } 200 \text { responden. Hasil }\end{array}$ \\
\hline & $\begin{array}{l}\text { penelitian menunjukkan bahwa perceived ease of use dan perceived usefulness berpengaruh positif } \\
\text { signifikan terhadap attitude toward using dan actual use. Perceived risk tidak berpengaruh signifikan } \\
\text { terhadap actual use aplikasi LinkAja. }\end{array}$ \\
\hline
\end{tabular}

\section{ANALYSIS OF TECHNOLOGY ACCEPTANCE MODEL IN LINKAJA APPLICATION}

\begin{abstract}
The potential for using e-money is huge and attracting attention as an alternative payment method around the world. The government through Bank Indonesia mobilizes the public to carry out the National Non-Cash Movement (GNNT). However, only certain segments of society that using e-money. This study aims to test the Technology Acceptance Model (TAM), perceived ease of use and perceived usefulness, adding perceived risk to determine the effect of attitude toward using and actual use on the use of the LinkAja application. The analysis method use Structural Equation Modeling (SEM) with the SmartPLS. This research was conducted using survey method and the sample was taken using a pirposive sampling technique to the respondents using the LinkAja application throughout Indonesia. Respondents obtained were 200 respondents. The results showed that perceived ease of use and perceived usefulness had a significant positive effect on attitude toward using and actual use. Perceived risk has no significant effect on the actual use of LinkAja application.
\end{abstract}

$\begin{array}{lr}\text { Alamat korespondensi : } & \text { ISSN } \\ \text { J. Siliwangi (Ringroad Utara) Jombor, Sleman, D.I. Yogyakarta 55285 } & 1979-4800 \text { (cetak) } \\ \text { E-mail: anggitestira@staff.uty.ac.id } & 2580-8451 \text { (online) }\end{array}$




\section{PENDAHULUAN}

Permintaan transaksi digital dan cashless di berbagai dunia semakin meningkat dan berdampak terhadap sikap pengguna terkait dengan mobile payment serta penerapannya telah mengalami perubahan drastis (Alalwan, Dwivedi, \& Rana, 2017). Berbagai penelitian menemukan bahwa konsumen lebih menyukai teknologi yang menyediakan layanan yang cepat, nyaman, dan bermanfaat dalam satu platform. Mobile payment menunjukkan teknik multiguna yang canggih dan mencakup fitur-fitur tersebut (Abhisek \& Hemchand, 2016). Pemerintah melalui Bank Indonesia juga menggerakkan masyarakat untuk melakukan Gerakan Nasional Non Tunai (GNNT), yaitu gerakan menggunakan alat pembayaran nontunai yang tujuannya menumbuhkan kesadaran sekaligus meningkatkan penggunaan nontunai di kalangan masyarakat, pelaku bisnis dan lembaga-lembaga pemerintah sehingga akan semakin terbentuk komunitas atau masyarakat yang lebih menggunakan instrumen nontunai (Usman, 2017).

Alasan utama masyarakat diharapkan bertransaksi secara elektronik adalah keamanan. Mengingat risiko yang sangat besar ketika membawa uang dalam jumlah banyak yang dapat mengundang kriminalitas. Ada beberapa kelebihan menggunakan e-money dibandingkan uang secara fisik. Pertama, dapat melakukan berbagai transaksi tanpa membawa banyak uang secara fisik. Kedua, dapat melakukan transaksi lebih cepat karena secara otomatis mengurangi saldo yang ada di e-money sesuai nilai transaksi. Namun, terdapat beberapa kekurangan menggunakan $e$ money. Pertama, belum semua transaksi dapat menggunakan e-money karena hanya dapat digunakan di merchant yang bekerja sama dengan penerbit $e$-money. Kedua, risiko seluruh uang hilang ketika pengguna kehilangan kartu jika tidak ada pengaman dengan password (Rosanti \& Mustafa, 2018). Sistem pembayaran dengan menggunakan $e$-money di Indonesia tergolong belum lama diterapkan. Bank Indonesia memberikan ijin penggunaan e-money dimulai pada tahun 2007. Hal ini dilakukan sebagai upaya mengurangi penggunaan transaksi secara tunai yang dikhawatirkan akan menimbulkan beban perekonomian. Perusahaan-perusahaan perbankan dan provider telekomunikasi menjadi penyelenggara dari sistem pembayaran ini. Provider telekomunikasi memanfaatkan intensitas pemakaian smartphone di era saat ini untuk masuk pada sistem pembayaran tersebut.

Akhir bulan Juni 2019, salah satu provider telekomunikasi bernama Telkomsel merilis aplikasi LinkAja yang dapat digunakan sebagai alat pembayaran nontunai. Aplikasi ini merupakan gabungan beberapa $e$-wallet milik BUMN dan T-Cash milik Telkomsel. LinkAja juga dapat digunakan untuk membeli bahan bakar di SPBU, mengirim uang, membeli pulsa, membeli paket internet, membayar tagihan seperti tagihan listrik dan air, dan membeli tiket transportasi umum seperti bus kota dan kereta api. Kereta Api Prameks merupakan transportasi umum yang sangat diminati masyarakat lokal sekitar Kutoarjo hingga Solo. Masyarakat dari berbagai kalangan ketika akan membeli tiket Kereta Api Prameks melalui aplikasi LinkAja. Masyarakat yang akan menggunakan Kereta Api Prameks agar lebih mudah dan tidak menunggu antrian terlalu lama dalam memesan tiket harus menggunakan aplikasi LinkAja, Berbagai penelitian telah mengkonfirmasi bahwa konsumen lebih menyukai teknologi yang menyediakan layanan cepat, nyaman, dan bermanfaat dalam satu platform. Dalam hal ini, layanan menggunakan pembayaran melalui mobile payment menunjukkan teknik multiguna lanjutan yang meliputi fitur-fitur tersebut (Abhisek \& Hemchand, 2016).

Penelitian ini bertujuan untuk menguji Technology Acceptance Model (TAM) yaitu perceived ease of use dan perceived usefulness yang menentukan sikap terhadap penggunaan (attitude toward using) terhadap penggunaan aktual (actual use) dari penggunaan aplikasi LinkAja sebagai alat pembayaran dalam transaksi sehari-hari bagi masyarakat yang belum terbiasa menggunakan transaksi nontunai. Selain itu, dalam penelitian ini juga ditambahkan persepsi risiko (perceived risk) untuk menentukan sikap terhadap penggunaan aplikasi LinkAja. 


\section{TELAAH PUSTAKA}

\section{Technology Acceptance Model (TAM)}

Technology Acceptance Model (TAM) merupakan salah satu model untuk menganalisis dan memahami faktor-faktor yang mempengaruhi diterimanya penggunaan teknologi. TAM menjelaskan hubungan sebab akibat antara keyakinan tentang manfaat suatu teknologi atau sistem informasi, kemudahan penggunanya, dan perilaku, serta tujuan penggunaan aktual teknologi atau sistem informasi tersebut (Davis, 1989). Peneliti telah banyak menggunakan model TAM dan UTAUT2 (Unified Theory of Acceptance and Use of Technology) untuk mengukur niat perilaku dan kepuasan pengguna (Duarte, Silva, \& Ferreira, 2018). UTAUT2 dikembangkan dengan mengintegrasikan konstruk yang dominan dari berbagai model yang berlaku untuk mengukur perilaku manusia terhadap adopsi sebuah teknologi. Beberapa model tersebut salah satunya adalah TAM. Model UTAUT menggunakan empat konstruk utama yaitu perceived usefulness, perceived ease of use, kondisi fasilitas, dan norma sosial. Sistem pembayaran dengan menggunakan telepon seluler dapat memberikan solusi kepada konsumen. Berbagai variabel telah digunakan di beberapa penelitian sebagai variabel terkait dengan adopsi suatu teknologi baru yaitu perceived ease of use, usefulness, trust, attitude, perceived risk, social influence, perceived hedonism dll. (Abhisek \& Hemchand, 2016).

\section{Perceived Ease of Use, Attitude Toward Using, dan Actual Use}

Perceived ease of use atau kemudahan penggunaan didefinisikan sebagai sejauh mana seseorang percaya bahwa menggunakan suatu teknologi akan bebas dari usaha (Davis, 1989). Pengaruh perceived ease of use terhadap attitude toward using diungkapkan dalam beberapa penelitian sebelumnya. Suatu sistem jika semakin mudah untuk digunakan, maka akan semakin besar niat terhadap penggunaan, dan semakin besar kemungkinan sistem tersebut digunakan. Penelitian sebelumnya tentang sistem pembayaran mobile payment menunjukkan bahwa perceived ease of use dan perceived usefulness adalah faktor yang paling berpengaruh untuk menentukan niat perilaku konsumen (Liébana-Cabanillas, Sánchez-Fernández, \& Muñoz-Leiva, 2014). Penelitian menunjukkan bahwa variabel persepsi manfaat berpengaruh positif dan signifikan terhadap minat menggunakan (Habsari Candraditya, 2013). Dari penjelasan tersebut dapat dirumuskan hipotesis bahwa persepsi kemudahan berpengaruh terhadap sikap terhadap penggunaan dan penggunaan aktual.

H1: Perceived ease of use berpengaruh positif terhadap actual use LinkAja

H4: Perceived ease of use berpengaruh positif terhadap attitude toward using LinkAja

\section{Perceived Usefulness, Attitude Toward Using, dan Actual Use}

Perceived usefulness atau kemanfaatan didefinisikan sebagai tingkat kepercayaan seseorang bahwa penggunaan sebuah sistem khusus akan meningkatkan performa pekerjaan (Davis, 1989). Semakin besar manfaat yang diberikan suatu sistem bagi penggunanya maka akan mempengaruhi sikap penggunanya untuk terus menggunakannya. Penelitian sebelumnya menunjukkan perceived ease of use, perceived usefulness, dan trust berpengaruh positif terhadap attitude toward using pada sistem tiket pesawat online (Renny, Guritno, \& Siringoringo, 2013). Perceived ease of use dan perceived usefulness juga berpengaruh positif signifikan terhadap niat penggunaan dan actual use (Chen \& Tseng, 2012). Dari penjelasan tersebut dapat dirumuskan hipotesis bahwa persepsi kemanfaatan berpengaruh terhadap sikap terhadap penggunaan dan penggunaan aktual.

H2: Perceived usefulness berpengaruh positif terhadap actual use LinkAja

H5: Perceived usefulness berpengaruh positif terhadap attitude toward using LinkAja 


\section{Perceived Risk, Attitude Toward Using, dan Actual Use}

Perceived Risk atau persepsi risiko merupakan kondisi ketidakpastian dari kegiatan transaksi secara online (Oentario, Harianto, \& Irawati , 2017). Masih banyak masyarakat di Indonesia yang belum terbiasa menggunakan transaksi secara nontunai. Sebagian masyarakat beranggapan bahwa transaksi nontunai yang menggunakan mobile payment atau e-money dan sejenisnya dari segi keamanan transaksi dinilai kurang aman karena sistem dapat membaca data yang sifatnya pribadi. Semakin besar risiko yang dihadapi oleh pengguna maka akan mempengaruhi sikap terhadap penggunaan dan mengurangi penggunaan aktual dalam kehidupan sehari-hari. Penelitian sebelumnya persepsi risiko akan mempengaruhi niat untuk menggunakan dan penggunaan aktual sistem dalam bertransaksi (Hansen, Saridakis, \& Benson, 2018). Dari penjelasan tersebut dapat dirumuskan hipotesis bahwa persepsi risiko berpengaruh terhadap sikap terhadap penggunaan dan penggunaan aktual.

H3: Perceived risk berpengaruh negatif terhadap actual use LinkAja

H6: Perceived risk berpengaruh negatif terhadap attitude toward using LinkAja

\section{Attitude Toward Using dan Actual Use}

Attitude toward using merupakan suatu sikap pengguna terhadap penggunaan sistem yang berbentuk penerimaan atau penolakan seseorang dalam menggunakan suatu teknologi dalam kesehariannya. Penelitian terdahulu menunjukkan attitude toward using berpengaruh positif terhadap niat untuk menggunakan dalam kasus ini adalah mobile wallet (Singh, Sinha, \& LiebanaCabanillas, 2020). Actual use merupakan bentuk respon psikomotor eksternal yang diukur oleh seseorang dengan penggunaan nyata (Davis, 1989). Actual use dapat diketahui melalui kondisi secara nyata penggunaan sistem informasi tersebut, antara lain: intensitas penggunaan sistem informasi, frekuensi penggunaan sistem informasi, maupun penggunaan sistem informasi yang sebenarnya secara terus-menerus. Dari penjelasan tersebut dapat dirumuskan hipotesis bahwa attitude toward using berpengaruh terhadap actual use.

H7: Attitude toward using berpengaruh positif terhadap actual use LinkAja

\section{METODE}

Penelitian ini dilakukan dengan metode survei yaitu menyebarkan kuesioner secara online kepada responden di seluruh Indonesia. Sumber data adalah data primer yang diperoleh langsung dari responden. Populasi dalam penelitian ini adalah semua pengguna LinkAja. Sampel penelitian diambil dengan menggunakan teknik purposive sampling dengan tujuan mendapatkan sampel yang representatif. Kriteria dalam pengambilan sampel yaitu responden menggunakan aplikasi LinkAja dan berumur 15-50 tahun. Sampel yang memenuhi kriteria sebanyak 200 responden, kemudian dilakukan analisis dengan model persamaan Structural Equation Modeling (SEM) menggunakan alat analisis SmartPLS.

Responden menjawab 19 item pertanyaan kuesioner. Setiap item petanyaan diukur menggunakan skala likert dengan interval 1 sampai dengan 6. Variabel independen dalam penelitian ini adalah perceived ease of use (PEU), perceived usefulness (PU), dan perceived risk (PR). Variabel intervening dalam penelitian ini adalah attitude toward using (ATU) dan variabel dependennya adalah actual use (AU). Model penelitian yang akan diuji disajikan di Gambar 1 dan definisi operasional variabel disajikan di Tabel 1. 


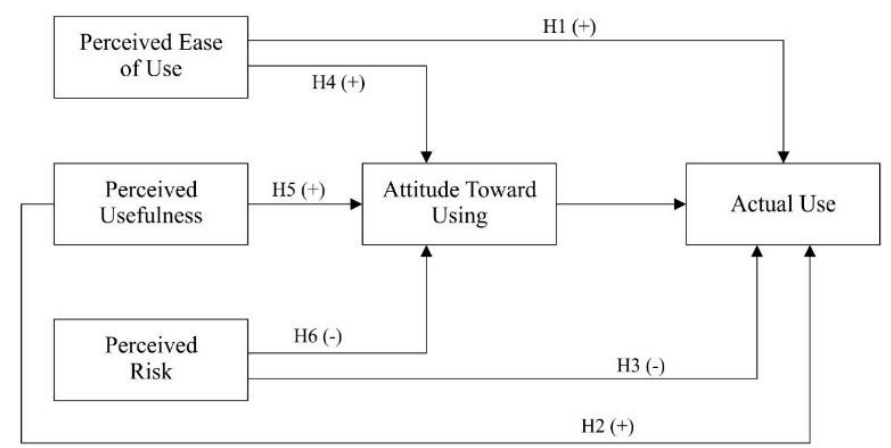

Gambar 1. Model Penelitian

Tabel 1. Definisi Operasional Variabel

\begin{tabular}{|c|c|c|c|}
\hline Variabel & Definisi & Indikator & Sumber \\
\hline $\begin{array}{l}\text { Perceived Ease of Use } \\
\text { (PEU) }\end{array}$ & $\begin{array}{l}\text { kemudahan penggunaan didefinisikan sebagai } \\
\text { keyakinan bahwa menggunakan suatu } \\
\text { teknologi akan bebas dari usaha }\end{array}$ & 4 item & $\begin{array}{l}\text { (Davis, 1989), (Singh, } \\
\text { Sinha, \& Liebana- } \\
\text { Cabanillas, 2020) }\end{array}$ \\
\hline $\begin{array}{l}\text { Perceived Usefulness } \\
\text { (PU) }\end{array}$ & $\begin{array}{l}\text { kemanfaatan didefinisikan sebagai keyakinan } \\
\text { bahwa penggunaan sebuah sistem khusus } \\
\text { akan meningkatkan performa pekerjaan }\end{array}$ & 4 item & $\begin{array}{l}\text { (Davis, 1989), (Singh, } \\
\text { Sinha, \& Liebana- } \\
\text { Cabanillas, 2020) }\end{array}$ \\
\hline Perceived Risk (PR) & $\begin{array}{l}\text { persepsi risiko merupakan sebagai prediksi } \\
\text { konsumen tentang potensi ketidakpastian dari } \\
\text { kegiatan transaksi secara online }\end{array}$ & 4 item & $\begin{array}{l}\text { (Oentario, Harianto, \& } \\
\text { Irawati , 2017), (Singh, } \\
\text { Sinha, \& Liebana- } \\
\text { Cabanillas, 2020) }\end{array}$ \\
\hline $\begin{array}{l}\text { Attitude Toward Using } \\
\text { (ATU) }\end{array}$ & $\begin{array}{l}\text { suatu sikap pengguna terhadap penggunaan } \\
\text { sistem yang berbentuk penerimaan atau } \\
\text { penolakan seseorang dalam menggunakan } \\
\text { suatu teknologi dalam pekerjaannya ataupun } \\
\text { kesehariannya }\end{array}$ & 4 item & $\begin{array}{l}\text { (Singh, Sinha, \& } \\
\text { Liebana-Cabanillas, } \\
\text { 2020) }\end{array}$ \\
\hline Actual Use (AU) & $\begin{array}{l}\text { bentuk respon psikomotor eksternal yang } \\
\text { diukur oleh seseorang dengan penggunaan } \\
\text { nyata }\end{array}$ & 3 item & (Mohammadi, 2015) \\
\hline
\end{tabular}

Sumber: disarikan dari berbagai jurnal

Analisis data dilakukan dengan menguji model pengukuran dan model struktural secara simultan menggunakan PLS. Pengujian model pengukuran meliputi uji validitas dan uji reliabilitas instrumen penelitian. Uji validitas terdiri dari 2, yaitu uji validitas konvergen dan uji validitas diskriman. Uji validitas konvergen dengan melihat Average Variance Expected (AVE) dan nilai loading masing-masing item nilainya harus lebih dari 0,5. Uji validitas diskriminan dengan melihat analisis AVE syaratnya adalah nilai kuadrat dari AVE setiap variabel harus lebih besar dari korelasi terbesar antara variabel tersebut dengan variabel lainnya. Uji reliabilitas dilakukan dengan melihat nilai Composite Reliability (CR) nilainya harus lebih besar dari 0,7. Selanjutnya, pengujian model struktural dilakukan untuk mencari nilai koefisien determinasi $\left(\mathrm{R}^{2}\right)$ syaratnya $\mathrm{R}^{2}$ lebih besar dari 0,10 dan memastikan bahwa model struktural yang dibangun sudah kuat (robust). Pengujian hipotesis dilakukan dengan melihat nilai t statistik, jika $\alpha=5 \%$ maka nilai t statistik harus lebih besar dari 1,96 (Syahputra \& Urumsah, 2019).

\section{HASIL DAN PEMBAHASAN}

Dari 200 kuesioner yang telah diisi oleh responden, sebanyak 50,5\% atau 101 orang berasal dari responden perempuan. Mayoritas responden yang menggunakan aplikasi LinkAja berasal dari kelompok usia 15-25 tahun atau sebanyak 84 responden. Persentase paling besar untuk jenjang pendidikan terakhir adalah sarjana/sederajat sebanyak 45,5\%. Mereka yang menggunakan aplikasi 
LinkAja sebagian besar bekerja sebagai karyawan BUMN/BUMS sebanyak $45 \%$ dan telah menggunakan aplikasi LinkAja lebih dari 1 tahun. Selain itu, dari 34 provinsi yang ada di Indonesia persentase paling banyak pengguna aplikasi LinkAja ada di Yogyakarta.

Tabel 2 menunjukkan hasil pengujian model pengukuran berupa uji validitas konvergen. Nilai loading masing-masing item lebih dari 0,5 dan pada Tabel 3 nilai AVE lebih dari 0,5. Hal ini menunjukkan variabel yang digunakan dalam penelitian ini memenuhi syarat uji validitas konvergen. Selain itu, pada Tabel 3 menunjukkan nilai CR lebih dari 0,7, artinya memenuhi syarat uji reliabilitas dan nilai kuadrat dari AVE setiap variabel lebih besar dari korelasi terbesar antara variabel tersebut dengan variabel lainnya artinya telah memenuhi syarat uji validitas diskriminan.

Tabel 2. Nilai Loading Factor

\begin{tabular}{lcc}
\hline Variabel & Item & Nilai Loading \\
\hline Perceived Ease of Use (PEU) & PEU 1 & 0,8729 \\
& PEU 2 & 0,8761 \\
& PEU 3 & 0,8339 \\
& PEU 4 & 0,8892 \\
\hline Perceived Usefulness (PU) & PU 1 & 0,8995 \\
& PU 2 & 0,9230 \\
& PU 3 & 0,9144 \\
& PU 4 & 0,9163 \\
\hline Perceived Risk (PR) & PR 1 & 0,9493 \\
& PR 2 & 0,8921 \\
& PR 3 & 0,8259 \\
& PR 4 & 0,7030 \\
\hline Attitude Toward Using (ATU) & ATU 1 & 0,8342 \\
& ATU 2 & 0,9081 \\
& ATU 3 & 0,9103 \\
& ATU 4 & 0,9000 \\
\hline Actual Use (AU) & AU 1 & 0,9003 \\
& AU 2 & 0,9418 \\
& AU 3 & 0,9424 \\
\hline
\end{tabular}

Sumber: Data Primer yang diolah, 2020

Tabel 3. Nilai Average Variable Expected (AVE), Composite Reliability (CR), dan Korelasi

\begin{tabular}{lccccccc}
\hline Variabel & AVE & CR & ATU & AU & PEU & PR & PU \\
\hline ATU & 0,7898 & 0,9375 & $\mathbf{0 , 8 8 8 7}$ & 0,0000 & 0,0000 & 0,0000 & 0,0000 \\
\hline AU & 0,8618 & 0,9492 & 0,6967 & $\mathbf{0 , 9 2 8 3}$ & 0,0000 & 0,0000 & 0,0000 \\
\hline PEU & 0,7539 & 0,9245 & 0,7158 & 0,5707 & $\mathbf{0 , 8 6 8 3}$ & 0,0000 & 0,0000 \\
\hline PR & 0,7183 & 0,9098 & $-0,0983$ & $-0,0637$ & $-0,1546$ & $\mathbf{0 , 8 4 7 5}$ & 0,0000 \\
\hline PU & 0,8342 & 0,9527 & 0,8009 & 0,7153 & 0,7350 & $-0,1566$ & $\mathbf{0 , 9 1 3 3}$ \\
\hline
\end{tabular}

Sumber: Data Primer yang diolah, 2020

Pengujian model struktural dilakukan dengan melihat nilai koefisien determinasi $\left(\mathrm{R}^{2}\right)$, nilai path coefficient dan nilai t-statistik. Pada Tabel 4 menunjukkan bahwa semua hipotesis didukung, kecuali H3 dan H6. Nilai t-statistik kurang dari 1,96 ( $\alpha=5 \%)$, kesimpulannya perceived risk tidak memiliki pengaruh signifikan terhadap attitude toward using dan actual use pada penggunaan aplikasi LinkAja. Nilai koefisisen jalur positif artinya semua hipotesis berpengaruh positif. Nilai $\mathrm{R}^{2}$ lebih dari 0,10 , artinya model struktural sudah kuat (robust). Nilai $\mathrm{R}^{2}$ untuk variabel attitude toward using yaitu 0,6781 artinya kemampuan variabel perceived ease of use, perceived 
usefulness, dan perceived risk mempengaruhi variabel attitude toward using sebesar $67,8 \%$ sisanya dipengaruhi oleh variabel lain. Selain itu, nilai $\mathrm{R}^{2}$ untuk variabel actual use yaitu 0,5560 artinya kemampuan variabel perceived ease of use, perceived usefulness, perceived risk, dan attitude toward using mempengaruhi variabel actual use sebesar 55,6\% sisanya dipengaruhi oleh variabel lain.

Tabel 4. Koefisien Determinasi, Path Coefficient, dan T-Statistik

\begin{tabular}{clccc}
\hline Hipotesis & & $\begin{array}{c}\text { Path } \\
\text { Coefficient }\end{array}$ & T-statistic & Hasil \\
\hline H1 & PEU $\rightarrow$ AU & 0,1023 & 2,7261 & Signifikan \\
H2 & PU $\rightarrow$ AU & 0,6485 & 17,9095 & Signifikan \\
H3 & PR $\rightarrow$ AU & 0,0536 & 1,5670 & Tidak Signifikan \\
H4 & PEU $\rightarrow$ ATU & 0,2798 & 7,3618 & Signifikan \\
H5 & PU $\rightarrow$ ATU & 0,6014 & 19,2513 & Signifikan \\
H6 & PR $\rightarrow$ ATU & 0,0391 & 1,8818 & Tidak Signifikan \\
H7 & ATU $\rightarrow$ AU & 0,3397 & 6,0930 & Signifikan \\
$\mathrm{R}^{2}$ ATU $=0,6781$ & & & & \\
$\mathrm{R}^{2}$ AU $=0,5560$ & & & & \\
$\alpha=5 \%$ & & & & \\
\hline
\end{tabular}

Sumber: Data Primer yang diolah, 2020

Hasil pengujian H1 menunjukkan bahwa perceived ease of use berpengaruh positif dan signifikan terhadap actual use LinkAja. Semakin mudah suatu sistem digunakan, maka akan semakin besar kemungkinan sistem tersebut digunakan. Hal tersebut dapat dilihat dari nilai path coefficient positif sebesar 0,1023 dan nilai t-statistik sebesar 2,7261 lebih besar dari 1,96 $(\alpha=5 \%)$. Hasil pengujian $\mathrm{H} 4$ menunjukkan bahwa perceived ease of use berpengaruh positif dan signifikan terhadap attitude toward using LinkAja. Semakin mudah suatu sistem digunakan, maka akan semakin besar niat terhadap penggunaan. Hal tersebut dapat dilihat dari nilai path coefficient positif sebesar 0,2798 dan nilai t-statistik sebesar 7,3618 lebih besar dari 1,96 ( $\alpha=5 \%)$. Oleh karena itu, H1 dan $\mathrm{H} 4$ dalam penelitian ini didukung. Pernyataan ini sesuai dengan penelitian sebelumnya yang dilakukan oleh (Liébana-Cabanillas, Sánchez-Fernández , \& Muñoz-Leiva, 2014) bahwa perceived ease of use dan perceived usefulness adalah faktor yang paling berpengaruh untuk menentukan niat perilaku konsumen dan (Habsari Candraditya, 2013) bahwa persepsi manfaat berpengaruh positif dan signifikan terhadap minat menggunakan.

Hasil pengujian $\mathrm{H} 2$ menunjukkan bahwa perceived usefulness berpengaruh positif dan signifikan terhadap actual use LinkAja. Semakin besar manfaat yang diberikan suatu sistem bagi penggunanya, maka pengguna akan terus untuk menggunakannya. Hal tersebut dapat dilihat dari nilai path coefficient positif sebesar 0,6485 dan nilai t-statistik sebesar 17,9095 lebih besar dari 1,96 $(\alpha=5 \%)$. Hasil pengujian H5 menunjukkan bahwa perceived usefulness berpengaruh positif dan signifikan terhadap attitude toward using LinkAja. Semakin besar manfaat yang diberikan suatu sistem bagi penggunanya, maka akan mempengaruhi sikap penggunanya untuk terus menggunakannya. Penelitian sebelumnya tentang pengaruh perceived usefulness terhadap attitude toward using dan actual use juga dilakukan dan hasilnya sejalan dengan penelitian yang dilakukan oleh (Renny, Guritno, \& Siringoringo, 2013) bahwa perceived usefulness mempegaruhi attitude toward usability pada kasus ini di reservasi tiket pesawat. Penelitian yang dilakukan oleh (Chen \& Tseng, 2012) menunjukkan bahwa perceived usefulness berpengaruh positif signifikan terhadap niat penggunaan dan actual use. Oleh karena itu, $\mathrm{H} 2$ dan $\mathrm{H} 5$ dalam penelitian ini didukung.

Hasil pengujian $\mathrm{H} 3$ menunjukkan bahwa perceived risk berpengaruh positif dan tidak signifikan terhadap actual use LinkAja. Semakin besar risiko yang dihadapi oleh pengguna tidak mengurangi penggunaan aktual dalam kehidupan sehari-hari. Hal tersebut dapat dilihat dari nilai 
path coefficient positif sebesar 0,0536 dan nilai t-statistik sebesar 1,5670 lebih kecil dari 1,96 ( $\alpha=$ 5\%). Hasil pengujian H6 menunjukkan bahwa perceived risk berpengaruh positif dan tidak signifikan terhadap attitude toward using LinkAja. Semakin besar risiko yang dihadapi oleh pengguna maka akan mempengaruhi sikap terhadap penggunaan dalam kehidupan sehari-hari. Hal tersebut dapat dilihat dari nilai path coefficient positif sebesar 0,0391 dan nilai t-statistik sebesar 1,8818 lebih kecil dari 1,96 ( $\alpha=5 \%)$. Penelitian yang dilakukan oleh (Afghani \& Yulianti , 2017) juga menunjukkan bahwa keamanan dan risiko terhadap adopsi e-banking tidak berpengaruh signifikan. Oleh karena itu, H3 dan H6 dalam penelitian ini ditolak.

Hasil pengujian $\mathrm{H} 7$ menunjukkan bahwa attitude toward using berpengaruh positif dan signifikan terhadap actual use. Semakin besar attitude toward using, maka semakin besar pula intensitas actual use. Hal tersebut dapat dilihat dari nilai path coefficient positif sebesar 0,3397 dan nilai t-statistik sebesar 6,0930 lebih besar dari 1,96 $(\alpha=5 \%)$. Penelitian yang dilakukan oleh (Jan, W de Jager, Ameziane, \& Sultan, 2019) menunjukkan bahwa attitude toward using berpengaruh signifikan terhadap smartphone advertising use. Oleh karena itu, $\mathrm{H} 7$ dalam penelitian ini didukung.

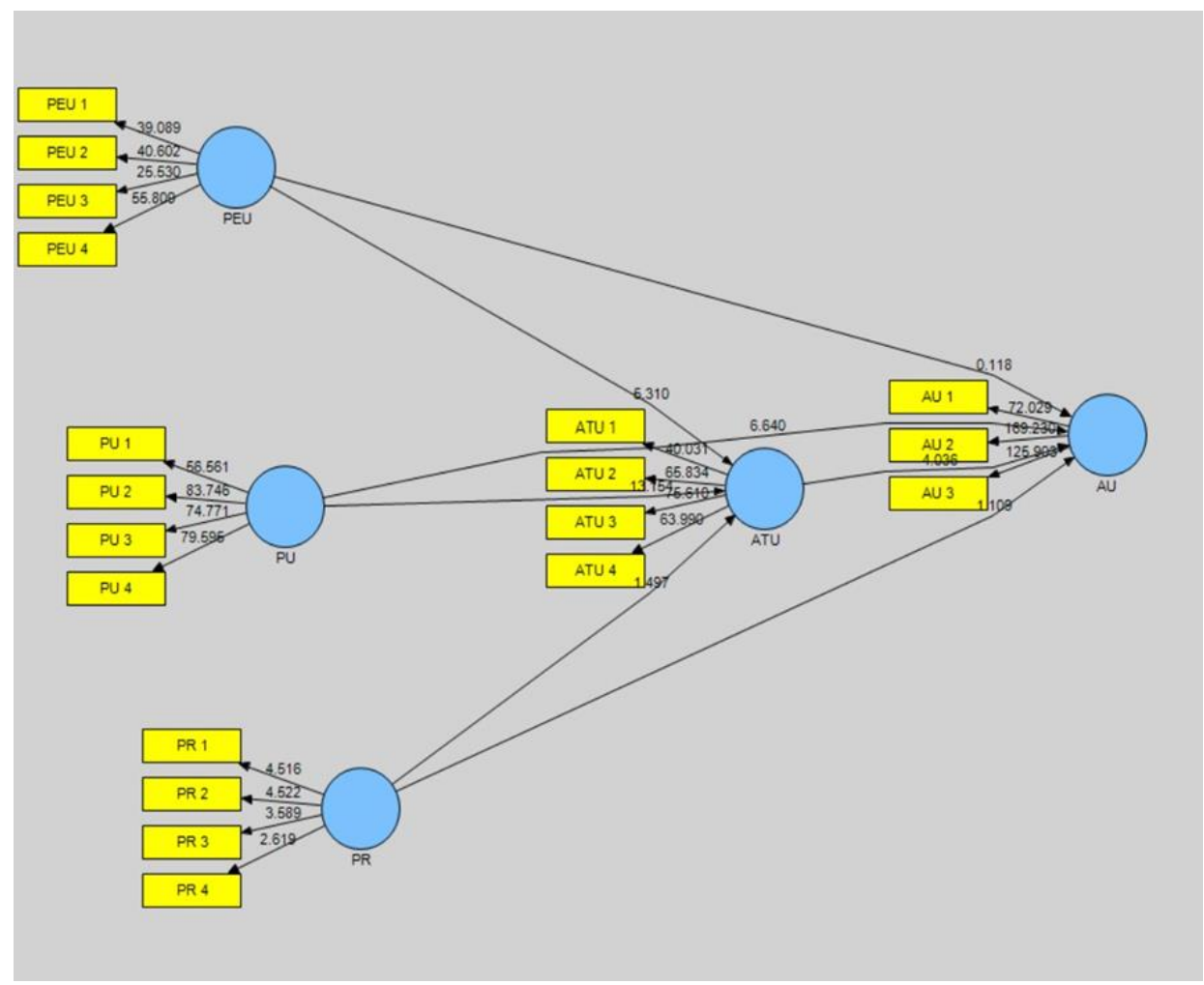

Gambar 2. Output Menggunakan SmartPLS

Penelitian ini bertujuan untuk menguji Technology Acceptance Model (TAM) yaitu perceived ease of use, perceived usefulness, dan perceived risk terhadap attitude toward using (sikap terhadap penggunaan) dan actual use (penggunaan aktual) dari penggunaan aplikasi LinkAja. Hasil penelitian menunjukkan bahwa perceived ease of use dan perceived usefulness berpengaruh positif dan signifikan terhadap attitude toward using dan actual use, sedangkan perceived risk tidak memiliki pengaruh signifikan.

Hasil penelitian ini secara signifikan mendukung elemen yang ada di dalam TAM yaitu perceive ease of use terhadap attitude toward using dan actual use. Pengguna yang memiliki persepsi kemudahan dalam menggunakan LinkAja akan bersikap untuk menerima adanya 
penggunaan teknologi. Kemudahan yang didapat seperti menghemat banyak waktu dan energi, tampilan dan menu yang terdapat di LinkAja juga mudah dipahami sehingga apa yang diperlukan oleh pengguna LinkAja dapat diberikan oleh aplikasi ini. Bagi pengguna yang memiliki mobilitas tinggi, aplikasi LinkAja dapat dijadikan sebagai solusi untuk memudahkan keperluan sehari-hari seperti membayar tagihan listrik dan air, membayar tagihan telepon, membeli pulsa atau paket data, membeli tiket transportasi umum seperti bus dan kereta api, membeli bahan bakar. Oleh karena itu, kemudahan yang diberikan oleh aplikasi LinkAja dapat digunakan dalam penggunaan transaksi sehari-hari. Penelitian sebelumnya mengenai penggunaan TAM dalam analisis minat perilaku penggunaan e-money menunjukkan bahwa salah satu faktornya yaitu perceived ease of use berpengaruh positif dan signifikan terhadap minat penggunaan e-money (Syahril \& Rikumahu, 2019).

Perceived usefulness atau persepsi manfaat didefinisikan sebagai sejauh mana seseorang percaya bahwa menggunakan suatu teknologi akan meningkatkan kinerja dari pekerjaannya (Yani, Lestari , Amalia, \& Puspita, 2018). Kinerja yang dipermudah ini dapat menghasilkan keuntungan yang lebih seperti hasil yang diperoleh akan lebih cepat dan lebih memuaskan dibandingkan dengan tidak menggunakan produk dengan teknologi tersebut. Aplikasi LinkAja memberikan kemudahan dalam menyelesaikan tugas penggunanya menjadi lebih efisien dan berguna dalam kehidupan sehari-hari. Semakin besar pengguna memiliki persepsi manfaat menggunakan aplikasi LinkAja, maka semakin besar penerimaan sikap terhadap penggunaan aplikasi LinkAja dan dampaknya dapat menjadi kebiasaan untuk menggunakannya dalam kehidupan sehari-hari. Penelitian yang dilakukan oleh (Hansen, Saridakis, \& Benson, 2018) juga mendukung bahwa perceived usefulness berpengaruh positif dan signifikan terhadap behavioral intention to use. Begitu pula dengan penelitian yang dilakukan oleh (Chen \& Tseng, 2012) bahwa perceived usefulness berpengaruh positif dan signifikan terhadap actual use.

Perceived risk atau persepsi risiko didefinisikan sebagai sebuah penilaian yang subjektif oleh seseorang terhadap kemungkinan dari sebuah kondisi yang tidak diinginkan dan seberapa khawatir individu dengan konsekuensi atau dampak yang ditimbulkan (Suhir, Suyadi, \& Riyadi, 2014). Dalam penelitian ini persepsi risiko cenderung kepada pengguna aplikasi LinkAja yang menggunakannya untuk melakukan berbagai macam bentuk transaksi yang dilakukan secara nontunai. Hasil penelitian ini, perceived risk memiliki pengaruh yang tidak signifikan terhadap attitude toward using dan actual use. Perceived risk tidak mempengaruhi sikap pengguna aplikasi LinkAja dalam memutuskan untuk melalukan transaksi secara nontunai dan tidak mempengaruhi pengguna aplikasi LinkAja untuk digunakan sebagai transaksi sehari-hari. Penelitian sebelumnya juga telah dilakukan bahwa keamanan dan risiko yang dirasakan oleh pengguna $e$-banking tidak signifikan (Afghani \& Yulianti , 2017), berbeda dengan penelitian yang dilakukan oleh (Hansen, Saridakis, \& Benson, 2018) bahwa perceived risk berpengaruh terhadap niat untuk menggunakan dan penggunaan aktual sistem dalam bertransaksi.

Attitude toward using didefinisikan sebagai suatu sikap pengguna terhadap penggunaan aplikasi LinkAja berbentuk penerimaan atau penolakan seseorang dalam menggunakan suatu teknologi dalam kesehariannya. Sikap pengguna sebagai pendorong utama dalam mempengaruhi adopsi pengguna atas teknologi aplikasi LinkAja dalam melakukan transaksi sehari-hari (Lin \& Chang, 2011). Penelitian ini menunjukkan bahwa attitude toward using aplikasi LinkAja terhadap actual use berpengaruh signifikan. Penelitian sebelumnya juga menunjukkan hasil yang sama dalam kasus mobile wallet (Singh, Sinha, \& Liebana-Cabanillas, 2020). 


\section{PENUTUP}

Penelitian ini bertujuan untuk menguji Technology Acceptance Model (TAM) yaitu perceived ease of use, perceived usefulness, dan perceived risk untuk mengetahui pengaruh terhadap attitude toward using dan actual use dari penggunaan aplikasi LinkAja sebagai alat pembayaran nontunai dalam transaksi sehari-hari. Penelitian ini menunjukkan bahwa perceived ease of use dan perceived usefulness memiliki pengaruh positif dan signifikan terhadap attitude toward using dan actual use aplikasi LinkAja. Kemudahan dan manfaat yang dirasakan oleh pengguna aplikasi LinkAja sebagai alat pembayaran nontunai seperti menghemat waktu dan tenaga sehingga menjadi lebih efektif dan efisien, promo menarik yang didapatkan oleh pengguna, merchant yang tergabung juga beraneka ragam dan pengguna dapat menyesuaikan sesuai kebutuhan dan golongan usia. Namun, perceived risk atau persepsi risiko ternyata tidak berpengaruh signifikan karena pengguna aplikasi LinkAja memiliki kesadaran yang tinggi terkait dengan keamanan yang ada di aplikasi LinkAja dan pemahaman yang baik dalam menggunakan aplikasi LinkAja dalam bertransaksi.

Penelitian selanjutnya diharapkan dapat menambahkan variabel lain yang diduga juga memiliki pengaruh signifikan terhadap penggunaan aplikasi LinkAja seperti persepsi kepuasan dan persepsi kepercayaan. Selanjutnya, diharapkan untuk menambah responden agar lebih representatif. Selain itu, juga diharapkan dapat meneliti lebih luas untuk seluruh financial technology di era digital saat ini karena manfaat dan kemudahan yang dirasakan oleh masyarakat dengan adanya perubahan bentuk uang sebagai alat transaksi pembayaran.

\section{DAFTAR PUSTAKA}

Abhisek, \& Hemchand, S. (2016). Adoption of Sensor-Based Communication for Mobile Marketing in India. Journal of Indian Business Research, 1(8), 65-76.

Afghani, M., \& Yulianti , E. (2017). Pengaruh Kepercayaan, Keamanan, Persepsi Risiko, serta Kesadaran Nasabah Terhadap Adopsi E-Banking di Bank BRI Surabaya. Journal of Business and Banking, 113-128.

Alalwan, A., Dwivedi, Y., \& Rana, N. (2017). Factors Influencing Adoption of Mobile Banking by Jordanian Bank Customers: Extending UTAUT2 with Trust. International Journal of Information Management, 3(37), 99-110.

Chen, H., \& Tseng, H. (2012). Factors that Influence Acceptance of Web-Based E-Learning System for The In-Service Education of Junior High School Teachers in Taiwan. Evaluation and Program Planning, 36, 398-406.

Davis, F. (1989). Perceived Usefulness, Perceived ease of Use, and Acceptance of Information System Technology. MIS Quarterly, 13(3), 319-340.

Duarte, P., Silva, S., \& Ferreira, M. (2018). How convenient is it? Delivering online shopping convenience to enhance customer perceived satisfaction and encourage e-. Journal of Retailing and Consumer Services, 44, 161-169.

Habsari Candraditya, I. (2013). Analisis Penggunaan Uang Elektronik (Studi Kasus Pada Mahasiswa Pengguna Produk Flazz BCA di Fakultas Ekonomika dan Bisnis Universitas Diponegoro. Diponegoro Journal of Management, 2(3), 1-11. 
Hansen, J., Saridakis, G., \& Benson, V. (2018). Risk, Trust, and The Interaction of Perceived Ease of Use and Behavioral Control in Predicting Consumers Use of Social Media for Transactions. Computers in Human Behavior, 80, 197-206.

Jan, M., W de Jager, J., Ameziane, A., \& Sultan, N. (2019). Appliying Technology Acceptance Model to Investigate the Use of Smartphone Advertising in Malaysia. Journal of Economics and Behavioral Studies , 11(1), 202-210.

Liébana-Cabanillas, F., Sánchez-Fernández , J., \& Muñoz-Leiva, F. (2014). Antecedents of the adoption of the new mobile payment systems: The moderating effect of age. Computers in Human Behavior, 35, 464-478.

Lin, J., \& Chang, H. (2011). The Role of Technology Readiness in Self-Service Technology Acceptance. Managing Service Quality: An International Journal, 21(4), 424-444.

Mohammadi, H. (2015). Investigating users'perspectives on E-learning: An Integration of TAM and IS success model. Computers in Human Behavior, 45, 359-374.

Oentario, Y., Harianto, A., \& Irawati , J. (2017). Pengaruh Usefulness, Ease of Use, Risk Terhadap Intention Buy Online Patisserie Melalui Consumer Attitude Berbasis Media Sosial di Surabaya. Jurnal Manajemen Pemasaran , 11(1).

Renny, Guritno, S., \& Siringoringo, H. (2013). Perceived Usefulness, Ease of use, and Attitude Towards Online Shopping Usefulness Towards Online Airlines Ticket Purchase. Procedia Social and Behavioral Sciences(81), 212-216.

Rosanti, N., \& Mustafa, M. (2018). Faktor Keengganan Pengguna Jasa Tol Beralih Menggunakan E-Money. Patria Artha Management Journal, 2(1), 23-40.

Singh, N., Sinha, N., \& Liebana-Cabanillas, F. (2020). Determining Factors in the Adoption and Recommmendation of Mobile Wallet Services in India: Analysis of the Effect of Innovativeness, Stress to Use, and Social Influence . International Journal of Information Management, 50, 191-205.

Suhir, Suyadi, I., \& Riyadi. (2014). Pengaruh Persepsi Risiko, Kemudahan dan Manfaat terhadap Keputusan Pembelian Secara Online. Jurnal Administrasi Bisnis, 8(1).

Syahputra, B. E., \& Urumsah, D. (2019). Deteksi Fraud Melalui Audit Pemerintahan Yang Efektif: Analisis Multigrup Gender dan Pengalaman. Jurnal Akuntansi dan Bisnis, 19(1), 31-42.

Syahril, W., \& Rikumahu, B. (2019). Penggunaan Technology Acceptance Model (TAM) dalam Analisis Minat Perilaku Penggunaan E-Money pada Mahasiswa Universitas Telkom. Jurnal Mitra Manajemen, 201-214.

Usman, R. (2017). Karakteristik Uang Elektronik Dalam Sistem Pembayaran. Jurnal Yuridika, $32(1)$.

Yani, E., Lestari , A., Amalia, H., \& Puspita , A. (2018). Pengaruh Internet Banking Terhadap Minat Nasabah dalam Bertransaksi Dengan Technology Acceptance Model. Jurnal Informatika, 5(1), 34-42. 